IRA-International Journal of Technology \& Engineering ISSN 2455-4480

Proceedings of the

International Conference on Science \& Engineering for Sustainable Development (2017)

Pg. no.266-278

Published by: Institute of Research Advances https://research-advances.org/index.php/IRAJTE

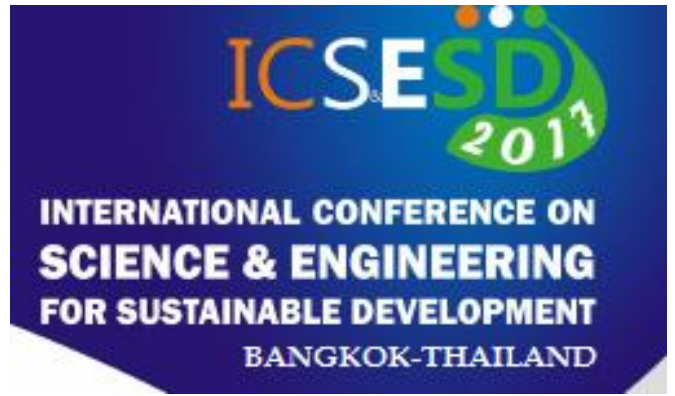

\title{
Experimental investigation on evaporation of R407C in a single horizontal smooth tube
}

\author{
M. D. Hambarde* ${ }^{1}$, Ramakant Shrivastava ${ }^{2}$, S.R.Thorat ${ }^{3}$, O.P.Dale ${ }^{4}$ \\ ${ }^{1,3,4}$ Maharashtra Institute of Technology, Kothrud, Pune(India) \\ ${ }^{2}$ Government College of Engineering, Aurangbad(India)
}

Type of Review: Originality Check \& Peer Review under the responsibility of the Scientific Committee of the Conference and The Institution of Engineers (India). DOI: http://dx.doi.org/10.21013/jte.ICSESD201726

\section{How to cite this paper:}

Hambarde, M., Shrivastava, R., Thorat, S., Dale, O. (2017). Experimental investigation on evaporation of $\mathrm{R} 407 \mathrm{C}$ in a single horizontal smooth tube. Proceedings of the International Conference on Science \& Engineering for Sustainable Development (2017), 266-278. doi: http://dx.doi.org/10.21013/ite.ICSESD201726

(C) International Conference on Science \& Engineering for Sustainable Development\& The Institution of Engineers (India).

\section{(cc) BY-NC}

This work is licensed under a Creative Commons Attribution-Non Commercial 4.0 International License subject to proper citation to the publication source of the work.

Disclaimer: The conference papers as published by the Institute of Research Advances (IRA) are the views and opinions of their respective authors and are not the views or opinions of the IRA. The IRA disclaims of any harm or loss caused due to the published content to any party. 


\section{ABSTRACT}

Due to higher ozone layer depletion potential of HCFC refrigerant, $R 22$ which has been mostly used in house hold refrigeration will be phased out by 2020 as per Montreal Protocol and UNFCCC Regulations. R407C, a zeotropic refrigerant from HFC category is a promising refrigerants in place of R22. Performance evaluation of $R 407$ is required to enhance its application in house hold refrigeration. Hence an experimental investigation is carried out to understand the heat transfer characteristics during flow boiling of R407C in a smooth horizontal tube of $13.386 \mathrm{~mm}$ inner diameter and $2 \mathrm{~m}$ length. The experiment is performed under the operating conditions; (i) mass flux range 100 to $300 \mathrm{~kg} \mathrm{~s}-1 \mathrm{~m}$-2; (ii) heat flux within range 2 to $7 \mathrm{kWm}-2$; (iii) temperature range at inlet to test section $-100 \mathrm{C}$ to $+100 \mathrm{C}$; (iv) average vapor quality within test section from 0.05 to 0.95.The effect of heat flux, mass flux, vapor quality, temperature glide on heat transfer coefficient, during evaporation of R407C are examined.

Keywords: flow boiling, heat transfer coefficient, investigation, mass flux, R407C, temperature glide.

\section{Introduction}

Pure HFCs and their mixture can be considered as promising substitute to HCFCs in the existing refrigeration equipment with minor effect to the environment.

R407C which is a mixture of HFCs can be used in the existing equipment with small changes in their design as a substitute to R22. Based on the preliminary theoretical analyses on thermodynamic properties, $\mathrm{R} 407 \mathrm{C}$ is the best possible substitute for R22, A Greco et.al [6].

According to C.Aprea et al.[5], R22 gives only 8 to $14 \%$ better performance than R407 C at the cost of higher ozone depletion potential $(\mathrm{ODP}=0.05)$. This little degradation in the performance of $\mathrm{R} 407 \mathrm{C}$ as compare to R22 can be overcome through heat transfer enhancement with proper design of evaporators and condensers. It required details investigation on heat transfer coefficient variation and pressure drop during flow boiling of R407C to create a huge data for design of evaporator and condenser.

Evaporation of pure refrigerants take place at constant temperature whereas in case of zeotropic mixture, the temperature progressively increases during evaporation. At initiation of evaporation (i.e. appearance of first bubble) the temperature is lower and at the end of evaporation (i.e. last bubble disappears) the temperature is highest. This difference in lowest and highest temperature during complete evaporation of zeotropic mixture is called as temperature glide.

The temperature at which the first bubble appears during evaporation is called bubble point and the temperature at which the last bubble disappears during evaporation is called dew point. Thus temperature glide is the difference between the bubble and the dew point temperature. This temperature glide distinguished the zeotropic mixtures like, R407C from pure HFCs.

The more volatile component of the zeotropic mixture first gets converted in to vapor and hence the less volatile liquid components of the mixture become rich, causing temperature glide during evaporation, $\mathrm{K}$. Stephan [14]. 
Many investigators carried out investigation on heat transfer enhancement in the evaporator using different surface geometries. Waldemar Targanski et al. [22] investigated R407C performance in microfin and corrugated tube, P.Rollmann et al.[18] investigated flow boiling behavior of R407C in microfin tube and Passos et al.[12] studied nucleate and convective boiling of R407C in plain and microfin tubes. Arijit Kundu et al. [2] investigated R407 C performance with different tube inclination.

A Greco et al. [6] compared energetic and thermodynamic performances of R22 and R407C and concluded that the energetic performance of $\mathrm{R} 407 \mathrm{C}$ is little poorer than that relating to $\mathrm{R} 22$. A Mostly research on evaporation heat transfer includes experimental investigation on two phase heat transfer coefficient and development of correlation for new refrigerants.

Reduced bubble growth rate as a result of mass transfer resistance effect, L.E.Scriven [15] and poor boiling site density as an effect of mixture composition, J.R.Thome et al.[13] suppressed the heat transfer coefficient of HFC mixture as compared to pure refrigerants under same operating condition, T.Y.Choi et al.[21].

Accurate heat transfer analysis during condensation and boiling along with associated frictional pressure drops are the prerequisite to avoid under and over -design of condensers and evaporators [4]. Julio Cesar Passos et al. [12] studied flow boiling of R407 $\mathrm{C}$ in a plain and microfin tube with outside diameter 7 and $12.7 \mathrm{~mm}$ and derived the inference that there is a $100 \%$ increase in heat transfer coefficient for microfin tube than that for the plain tube and this growth in heat transfer coefficient is greater than the heat transfer surface area of the microfin tubes for the surface factor1.46. The dry out phenomenon occurs early, around the vapor quality $63-78 \%$ for microfin tube as compare to plain tube where it occurs around 78 $70 \%$ vapor quality[4].

Enrique Torrella et al.[10] presented the work on evaporation of $\mathrm{R} 407 \mathrm{C}$ in a refrigerating vapor compression plant's shell and tube evaporator using effectiveness-NTU method; concluding that the evaporating temperature presides the heat transfer coefficient than refrigerant's mass flow rate in the test range. S.Wellsandt et al.[19] performed investigation on evaporation of R407C and R410A in a herringbone microfin tube with an outer diameter of $9.53 \mathrm{~mm}$ with end remark that at equal mass flow rates and temperatures the heat transfer coefficients for R410A and $\mathrm{R} 407 \mathrm{C}$ are generally lower than that for R134a and starts to degrade earlier than R134a. F.C. Hsieh et al.[11] and C.A. Chen et al.[7] carried out the experiments on R407C in annular duct during saturated flow boiling and sub cooled flow boiling respectively.

C.Apera et al.[5] compares experimentally R407C and R417A as substitute to R22 and concluded that at low vapor quality and evaporating pressure $\mathrm{R} 407 \mathrm{C}$ heat transfer coefficients are lower than those of R407C but at high vapor quality and low pressure R407C heat transfer coefficients matches with those of R417A.

Comparative experimental study of Arijit Kundu et al. [1] on zeotropic mixture R407C, quasi-azeotropic blend R410A and pure R134a, quoted that R407C always lags R410A and R134a in heat transfer performance.

Most of investigators [1],[3],[4],[8],[16] carried out investigation on flow boiling of R407Cin a horizontal plain tube with an internal tube diameter not more than $12.5 \mathrm{~mm}$. In the present study the experimental investigation on evaporation of $\mathrm{R} 407 \mathrm{C}$ is carried out in a single horizontal plain tube with13.386 mm internal diameter, which is a rare. The experiment is performed under different operating condition of heat flux, mass flux and saturation pressure and vapor quality as mentioned in table 1 . The purpose of the present study on flow boiling heat transfer of R407C is to understand: (1) variation of heat transfer 
coefficient with vapor quality at different operating pressure, mass flux and heat flux, (2) effect of temperature glide across the test section on heat transfer coefficient and vapor quality at different mass flux, heat flux and pressure.

\section{EXPERIMENTALL APPARATUS AND INSTRUMENTATION}

\section{A. Test facility}

The experimental test facility was a vapor compression refrigeration plant specially designed for investigation of flow boiling heat transfer phenomenon under different operating conditions of mass flux, heat flux, and pressure. A schematic layout of experimental test facility is shown in figure1.

The experimental test facility consists of a loop that provides controlled mass velocity and it was designed to test different refrigerants at a wide range of flow conditions. The main part of the loop has a turbine flow meter, a pre-heater section, the test section and the after evaporator section. The secondary part consists of a condenser, a refrigerant receiver, filter-drier, expansion valve, bypass valve and compressor. The pre-heater control the vapor quality of refrigerant entering the test section. It consists of cooper tube in the form of coil and immersed in to the glycol-water bath. The heat is applied on the copper coil with the help of three heaters immersed in to the water-glycol bath as shown in figure1.The uniform heat flux condition on the copper coil is assured with the help of stirrer, steering the water-glycol solution. In the pre-heater, the heat input from heater to the refrigerant through water glycol solution is precisely control by solid state relay and PID controller.

Test Evaporator section is a tube in pipe structure in which a horizontal copper test tube of $13.386 \mathrm{~mm}$ inner diameter and $15.875 \mathrm{~mm}$ outer diameter with $2 \mathrm{~m}$ length is passed through a stainless steel pipe of $100 \mathrm{~mm}$ inner diameter and $103.2 \mathrm{~mm}$ outer diameter and $2 \mathrm{~m}$ length. Two straight heating rods, each of 0.9 meter in length are inserted in to the stainless pipe from its extreme ends parallel to copper tube.

\section{TABLE I}

\section{OPERATING RANGE OF TEST PARAMETERS}

\section{Parameters}

Refrigerant mass flux

Heat Flux

Temperature range at inlet to evaporator test section

Pressure range (absolute) at inlet to evaporator test section

vapor quality, $\mathrm{x}$
Range
$100-350 \mathrm{Kg} \mathrm{m}^{-2} \mathrm{~s}^{-1}$
$1.4-8 \mathrm{~kW} \mathrm{~m}^{-2}$
-14 to $6.5^{0} \mathrm{C}$
$3.5-7$ bar,
$0.05-0.9$

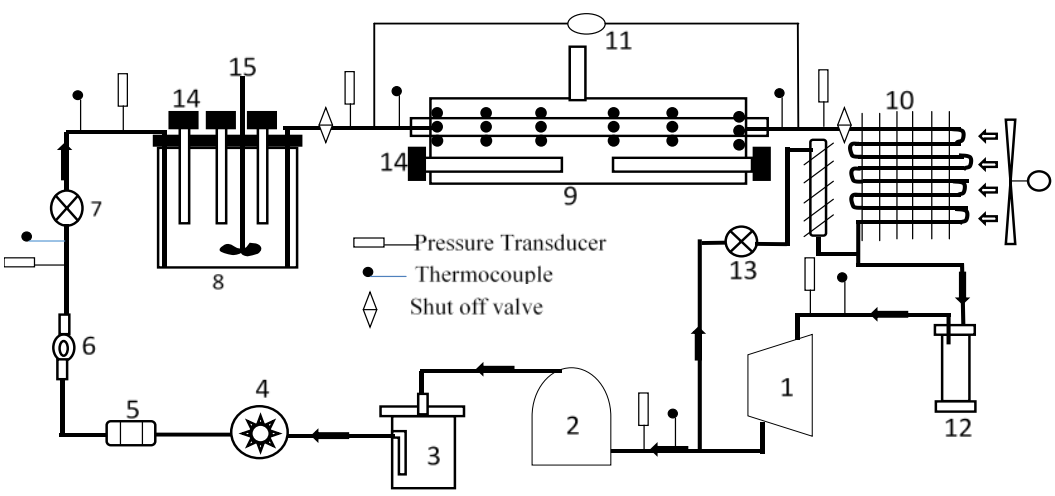


1-Compressor, 2-Condenser, 3-Receiver, 4-Flow meter,5-Drier,6-Sight Glass,7-Manual Expansion Valve, 8- Pre Evaporator,9-Test Section, 10- After Evaporator,11- Differential Pressure Transducer,12Accumulator,13-By Pass Valve,14- Heater,15- Stirrer

Fig. 1. Experimental test facility

The annular gap between stainless pipe and copper tube is filled with water-glycol solution. The uniform heat flux condition is assured by uniform heating of water glycol solution along the length of copper tube by two heating rods. The heat flux applied on the copper tube through water glycol solution is precisely controlled by controlling the voltage and current through solid state relay controller. The voltage and current of pre-evaporator heaters and test evaporator section heaters are measured by standard clam meter.

At six axial positions on copper test tube, $\mathrm{T}$ type thermocouples are brazed circumferential on its outer surface separated by $90^{\circ}$ one another as shown in figure 2 .

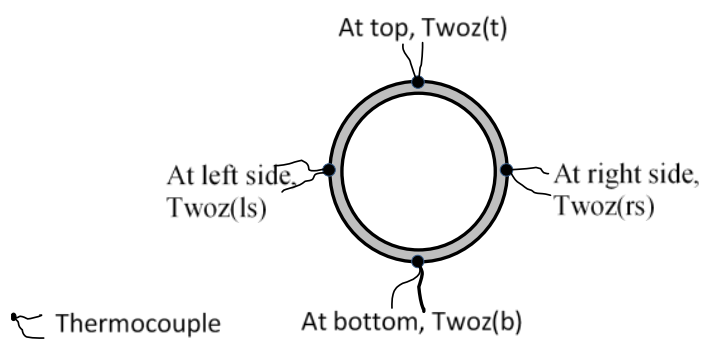

Fig. 2. Cross section of test section tube

Downstream the test section there is an after evaporator with fan control. The required super heat of refrigerant at the inlet to compressor is controlled by sensible heating through fan speed in after evaporator. Pre-heater and test section and low pressure line are thermally insulated by flexible elastorneric nitrile foamed rubber for reducing heat losses to the surroundings. The refrigerant enters the pre-heater in the condition of subcooled liquid and achieves the saturation condition at its outlet. This condition defines the vapor quality at the test section inlet and varies according to the heat flux imposed in the pre-heater. The pressure and temperature measurements at the inlet and outlet of the pre-heater are carried out by two absolute pressure transducers (accuracy $0.25 \%$ FS) and two thermocouples of T type, in direct contact with the refrigerant.

Refrigerant temperatures at the inlet and outlet of test section tube as well as on its outer surface are measured by $\mathrm{T}$ type thermocouples. The differential pressure transducer (accuracy $\pm 0.1 \%$ of URL) measured pressure drop across the test tube section. Oval gear flow meter (accuracy $\pm 0.15 \%$ FSD) is fitted in high pressure liquid line after condenser to measure mass flow rate of refrigerant. The pressure transducers, thermocouples, mass flow meter and are connected to National Instrument's data acquisition system (NI 9207 8-ch(V)+ 8-ch(I) combo module, NI 921316 ch TC ). Lab View Academic Premium Suite interface is used for data processing.

\section{DATA REDUCTION}

The local heat transfer coefficient is calculated from newton's law of cooling as shown by equation (1):

$$
h=\frac{q}{T_{w i}-T_{\text {sat }}}
$$

where,

$q=\frac{Q_{T S}}{A_{S}} \&$

$Q_{T S}=Q_{H}-Q_{L}$ 
$\mathrm{Q}_{\mathrm{H}}$, heat input from heater is calculated as a product of current and voltage across the heater and $\mathrm{Q}_{\mathrm{L}}$, heat loss to surrounding from test evaporator is taken from the heat leakage calibration curve obtained for test evaporator's heat leakage test.

$T_{w i}=T_{W O}-\frac{\mathrm{Q}_{T S}}{2 \pi L \mathrm{~K}} \ln \frac{D_{o}}{D_{i}}$

$T_{W O}$, is the average outside tube wall temperature over the entire length of test section tube and is calculated as shown by equation (5) :

$T_{W O}=\frac{T_{W O Z}{ }_{1}+T_{W O Z}{ }_{2}+\cdots \ldots \ldots \ldots T_{W O Z} 6}{6}$

$T_{W O Z}$, is the average outside tube wall temperature at the given location ' $\mathrm{Z}$ ' on the copper tube and is calculated as:

$T_{W O Z}=\frac{T_{W O Z(t)}+T_{W O Z(b)}+T_{W O Z(l s)}+T_{W O Z(r s)}}{4}$

$T_{\text {sat }}$ is the saturation temperature taken as the mean of bubble and dew point temperature corresponding to pressure in the test tube section. The vapor quality in the test tube section is taken as the average of vapor quality at inlet and out let of test section tube, as expressed by equation (7):

$x_{\text {avg }}=\frac{x_{\text {in }}+x_{\text {out }}}{2}$

where, $x_{i n}$ is the vapor quality at the inlet to test section and is calculated as:

$x_{i n}=\frac{e_{\text {in }}-e_{h f, i n}}{e_{h f g, i n}}$

Similarly, vapor quality at the outlet to the test section tube is calculated as:

$x_{\text {out }}=\frac{e_{\text {out }}-e_{\text {hf }, \text { out }}}{e_{\text {hfg }, \text { out }}}$

Enthalpies at the inlet, $e_{\text {in }}$ and outlet, $e_{\text {out }}$ to test section tube are found from REFPROP 7.0 at the pressure and temperature condition measured by thermocouples and pressure transducers.

TABLE II

ACCURACY OF MEASURING INSTRUMENTS

\begin{tabular}{|c|c|c|c|}
\hline $\begin{array}{l}\text { Variable } \\
\text { Temperature }\end{array}$ & $\begin{array}{l}\text { Instrument } \\
\text { T-type } \\
\text { thermocouple }\end{array}$ & $\begin{array}{l}\text { Accuracy } \\
\pm 0.375^{\circ} \mathrm{C}\end{array}$ & $\begin{array}{l}\text { Range } \\
-40{ }^{\circ} \mathrm{C} \\
\text { to } 150 \\
{ }^{0} \mathrm{C}\end{array}$ \\
\hline Pressure & Piezo Resistive & $\begin{array}{l} \pm 0.25 \% \\
\text { FS }\end{array}$ & $\begin{array}{l}0 \text { to } 20 \\
\text { bar } \\
\text { (Abs) }\end{array}$ \\
\hline Differential & Piezo Resistive & $\pm 0.1 \%$ & 0 to 0.3 \\
\hline Pressure & & of URL & Bar \\
\hline Mass flow & Oval gear- & $\pm 0.15 \%$ & 20 to \\
\hline rate & $\begin{array}{l}\text { Positive } \\
\text { displacement }\end{array}$ & FSD & $\begin{array}{l}300 \\
\text { LPH }\end{array}$ \\
\hline Voltage & Clamp Meter & $\pm 1.2 \%$ & 0 to 250 \\
\hline Current & Clamp Meter & $\begin{array}{l} \pm 2.5 \% \\
\text { F.S. }\end{array}$ & $\begin{array}{l}0 \text { to } \\
200 \mathrm{~A}\end{array}$ \\
\hline
\end{tabular}




\section{Results}

In the present work, effect of operating conditions: saturation pressures, mass flux, heat flux on heat transfer coefficient and vapor quality are experimentally investigated. Through 17 test runs, near about 180 data points have been obtained for experimental investigation. The discussion on the experimental results is mainly focused on an effect of saturation pressure, mass flux and heat flux on heat transfer mechanism during flow boiling of R407C. Temperature glide across the test section tube is examined for different operating conditions.

\section{A. Effect of operating pressure on flow boiling heat transfer}

The experiment is performed between operating pressure range: $3.5-7.0$ bar. Figure 3(a) and 3 (b) shows an effect of different operating pressures on heat transfer coefficient varying with vapor quality at the mass flux of $203.64 \mathrm{kgm}^{-2} \mathrm{~s}^{-1}, 157.1 \mathrm{kgm}^{-2} \mathrm{~s}^{-1}$ and heat flux of $1.4 \mathrm{kWm}^{-2}$ and $4.19 \mathrm{kWm}^{-2}$ respectively. From figure 3(a) and 3(b), it is seen that heat transfer coefficient increases with increase in operating pressure. The variation of heat transfer coefficient with vapor quality revealed that there is an increment in the heat transfer coefficient within lower vapor quality region (i.e. $\mathrm{x}=0.1$ to 0.4 ) and then decrement up to 0.6 or 0.7 vapor quality at all operating pressures. At higher vapor quality region (vapor quality more than 0.7 ) it seemed that heat transfer coefficients merged for all operating pressures. Dominating nucleate boiling in the low quality region is responsible for the improvement of heat transfer coefficient within this region. At the termination of nucleate boiling around 0.4 vapor quality, the convective boiling is commenced and as the more volatile component R32 mostly get vaporized, it creates the mass transfer resistance to flow. As a consequences the heat transfer coefficient get suppressed, which can be seen between vapor qualities 0.4 to 0.7 . Due to vapor dry out after 0.85 vapor quality, the sudden drop of heat transfer coefficient is seen.

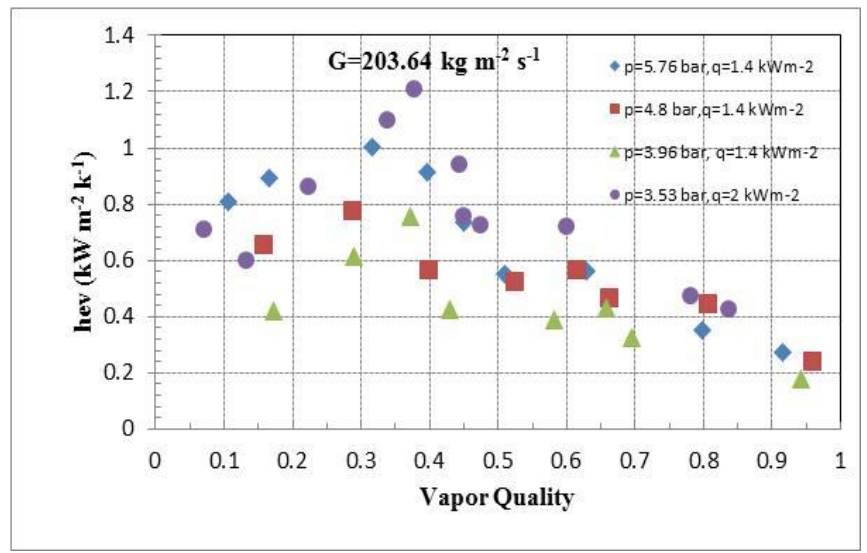

Fig. 3(a). Heat transfer coefficient of R407C varying with different pressure at $\mathrm{G}=203.64 \mathrm{~kg} / \mathrm{m}^{2} \mathrm{~s}$ and $\mathrm{q}=$ $1.4 \mathrm{~kW} / \mathrm{m}^{2}$ and $2 \mathrm{~kW} / \mathrm{m}^{2}$. 


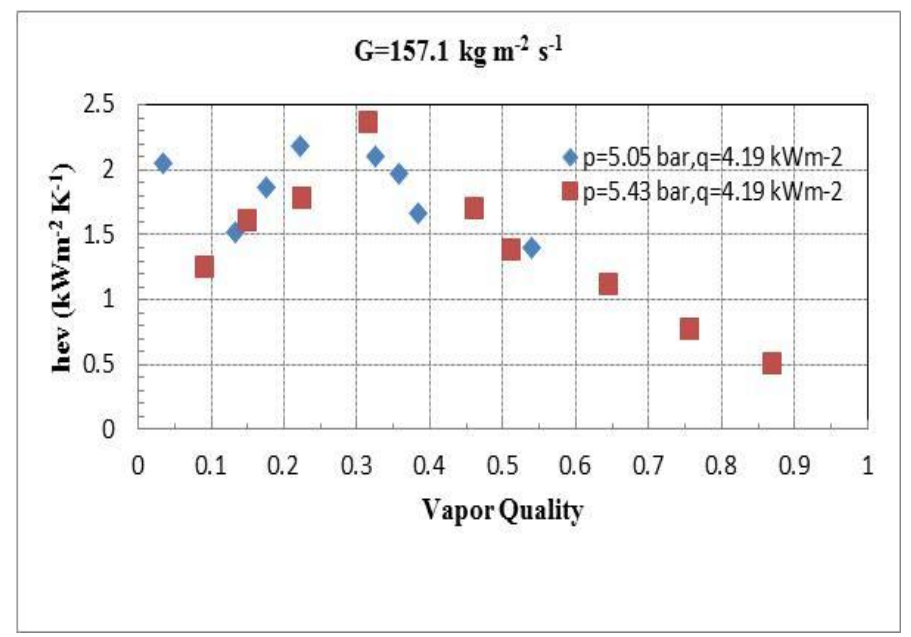

Fig. 3(b). Heat transfer coefficient of R407C varying with different pressure at $G=157.1 \mathrm{~kg} / \mathrm{m}^{2} \mathrm{~s}$ and $\mathrm{q}=$ $4.19 \mathrm{~kW} / \mathrm{m}^{2}$.

B. Effect of mass flux on flow boiling heat transfer

In the experimental facility mass flux is varied through bypass valve and expansion valve. Figure 4 shows the effect of different mass flux with increasing pressure on heat transfer coefficient with respect to vapor quality at a constant heat flux of $4.14 \mathrm{kWm}^{-2}$. It can be seen that there is no significant effect of mass flux and pressure on heat transfer coefficient in a high vapor quality region (vapor quality greater than 0.7 ). The influence of mass flux on the heat transfer coefficient can be seen in the lower vapor quality region only. The heat transfer coefficient increases with increasing the mass flux within very short vapor quality range of 0.05 to 0.3 . Poor nucleation site density [13] with increase in mass flux terminates the nucleate boiling and hence ceased the further improvement in heat transfer coefficient within lower quality region. The overall improvement in heat transfer coefficient with increase in mass flux is due to the flow acceleration during convective boiling as an effect of increased mass velocity which overcomes the mass transfer resistance due to mixture composition.

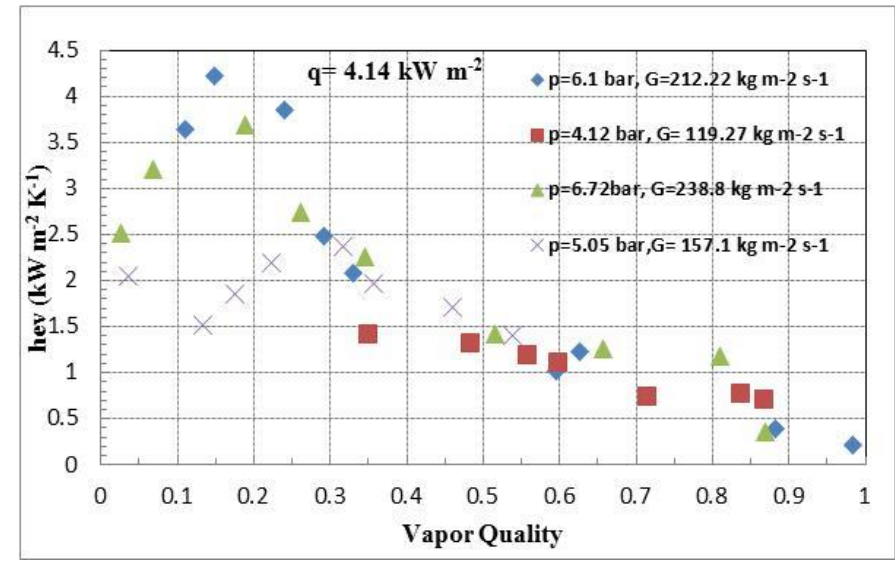

Fig. 4. Heat transfer coefficient of R407C varying with different mass flux and pressure at $\mathrm{q}=$ $4.14 \mathrm{~kW} / \mathrm{m}^{2}$. 


\section{Effect of heat flux on flow boiling heat transfer}

From figure 5, it is seen that in general the heat transfer coefficient increases with increase in heat flux. For a given heat flux condition the increase in the heat transfer coefficient is seen up to maximum vapor quality 0.4. In the initial phase of flow boiling as nucleate boiling is dominating (Chen J C [9], M.M.Shah [17] and S.G.Kandlikar [20]) it controls rise of wall temperature, but at the same time as more volatile component R32 start to vaporize, it increases local saturation temperature. As a consequence the wall super heat decreases, increasing heat transfer coefficient. In the second phase of flow boiling usually vapor quality greater than 0.4 as seen in the figure 5, nucleate boiling terminates and convective boiling take a charge of heat transfer mechanism. Convective heat transfer take place at the vapor liquid interface during convective boiling which controls the local saturation temperature, but at the same time the wall temperature increases as the evaporation or boiling phenomenon shift from wall liquid interface to liquid vapor interface. This increase in the wall temperature increases wall superheat (i.e. $\mathrm{T}_{\text {wall }}-\mathrm{T}_{\text {sat }}$ ) and hence decrease in heat transfer coefficient is seen.

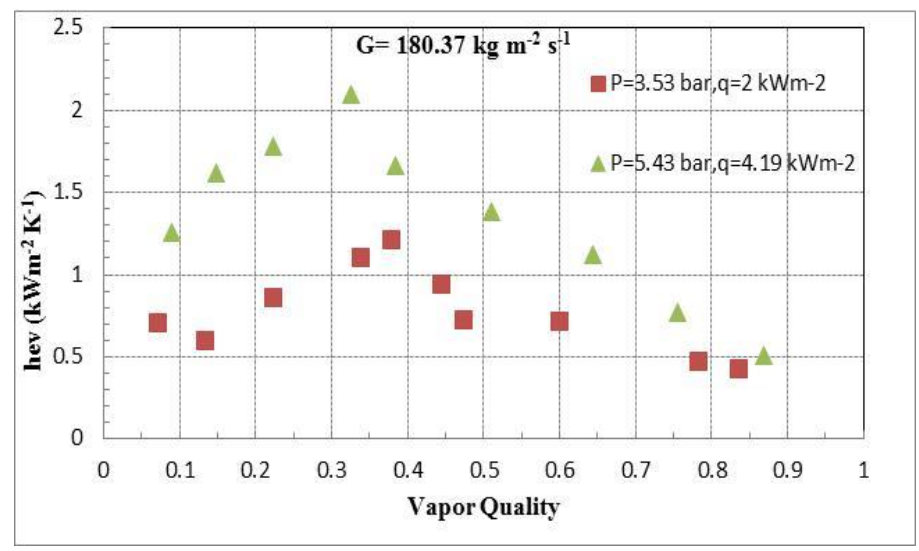

Fig. 5. Heat transfer coefficient of R407C varying with different heat flux and pressure at $\mathrm{G}=180.37$ $\mathrm{kg} / \mathrm{m}^{2} \mathrm{~s}$.

\section{Temperature glide (across test tube section) examination}

As initially said temperature glide is the characteristics of zeotropic mixture which distinguish it from pure HFC's. Proportion of mixture component and their thermo physical properties decides temperature glide for particular zeotropic or azeotropic mixtures. In the present experimental study the temperatures are measured at the inlet and outlet of test section tube by $\mathrm{T}$ - type thermocouples with its measuring ends in contact with the refrigerant flowing through test section tube. The difference between inlet and outlet temperature of refrigerant across the test section tube is considered as temperature glide for examination. Figure 6(a) and figure 6(b) shows variation in temperature glide with respect to vapor quality for different mass flux, heat flux and operating pressures. 


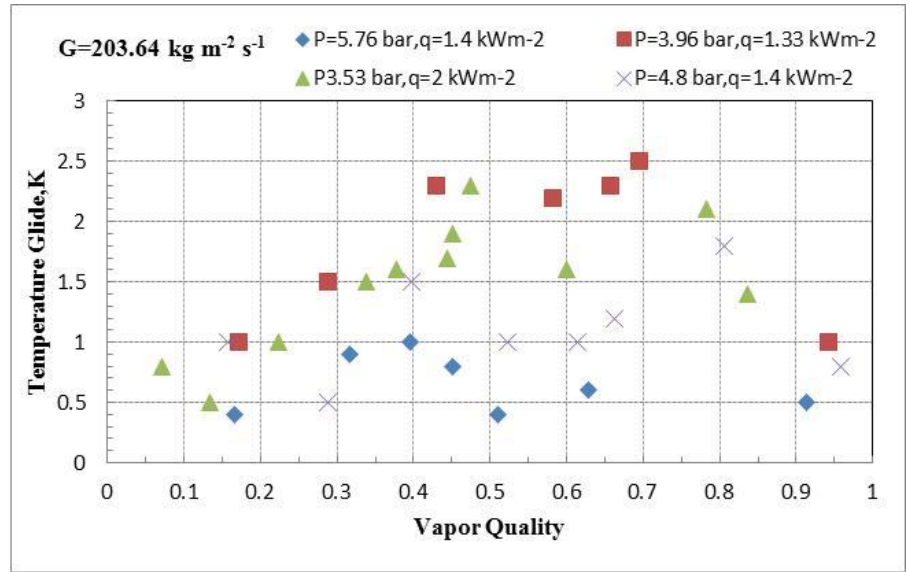

Fig. 6(a). Temperature glide of R407C across the test section tube at varying pressure and heat flux.

The maximum temperature glide across the test tube section is seen as $4.0 \mathrm{~K}$, as complete evaporation of refrigerant (i.e. complete dry out) is not achieved in the test tube section. It is seen that in general the temperature glide increases with increase in vapor quality, but in the middle range of vapor quality (i.e. vapor quality 0.3 to 0.65 ) it shows slight decrease in temperature glide. During initial range of vapor quality as earlier said nucleate boiling is dominating heat transfer mechanism, in which more volatile component evaporate first and hence less volatile components of mixture become rich increasing the temperature glide [14]. It can be seen from the general observation of all the experimental results that the heat transfer coefficient stars to drop after vapor quality of 0.3 and 0.4 , at which nucleate boiling terminates and convective boiling holds the control of heat transfer mechanism. During this convective boiling heat transfer the evaporation of liquid take place at the liquid vapor interface accelerating the flow as a result, you can see the decreasing temperature glide at the commencement of convective boiling (i.e. within vapor quality 0.3 to 0.65 ).

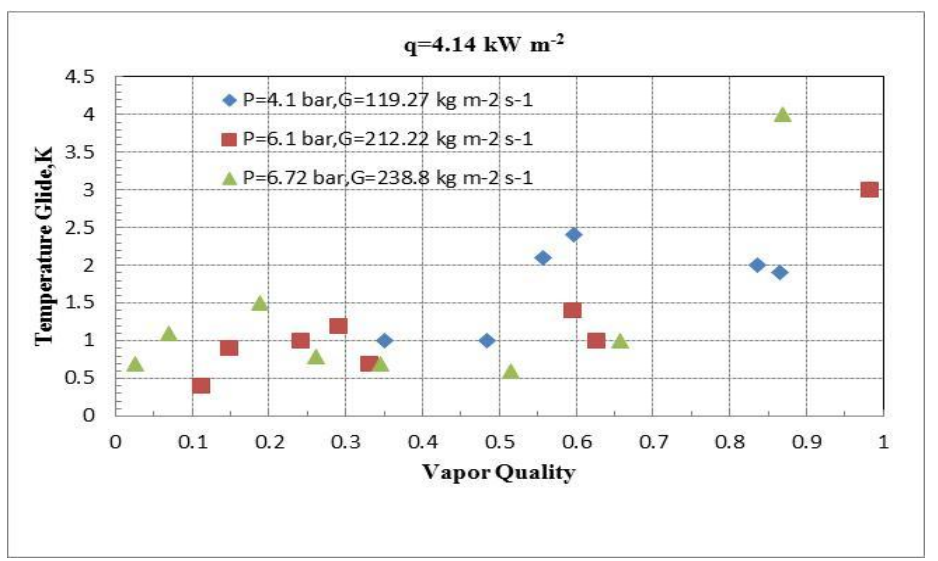

Fig. 6(b). Temperature glide of R407C across the test section tube at varying pressure and heat flux.

\section{Conclusions}

Experimental investigation on evaporation of $\mathrm{R} 407 \mathrm{C}$ in a single horizontal smooth tube is carried out to understand the effect of operating pressures, mass flux and heat flux under operating conditions: (i) mass flux- $100-350 \mathrm{Kg} \mathrm{m}^{-2} \mathrm{~s}^{-1}$ (ii) heat Flux- $1.4-8 \mathrm{~kW} \mathrm{~m}^{-2}$ (iii) temperature range in evaporator test section 
$=-10$ to $10{ }^{0} \mathrm{C}$ (iv) Pressure range in evaporator test section $=3-7$ bar, (v) vapor quality, $\mathrm{x}=0.05-$ 0.9.Temperature glide across the test section copper tube is examined during evaporation of R407C.

From experimental results, following inferences can be derived.

1. Heat transfer coefficient increases with increase in operating pressure. Variation of heat transfer coefficient at a given pressure revealed that there is an increment in the heat transfer coefficient within lower vapor quality region (i.e. $\mathrm{x}=0.1$ to 0.4 ) and then decrement with vapor quality up to 0.6 or 0.7 . Termination of nucleate boiling around 0.4 vapor quality and mass transfer resistance with increasing vapor quality, there after suppressed the heat transfer coefficient.

2. The heat transfer coefficient increases with increasing the mass flux within very small vapor quality range of 0.05 to 0.3 .Poor nucleation site density terminates the nucleate boiling earlier and hence improvement in heat transfer coefficient is seen only lower vapor quality range.

3. For a given heat flux condition the increase in the heat transfer coefficient is seen up to maximum vapor quality 0.4 . As nucleate boiling is dominating, it controls rise of wall temperature within low vapor quality region and decreases wall super heat and hence increases heat transfer coefficient within this region.

4. In general the temperature glide increases with increase in vapor quality, but in the middle range of vapor quality (i.e. vapor quality 0.3 to 0.65 ) it shows slight decrease. Evaporation of more volatile component R32 during flow boiling of R407 C makes less volatile component mixture rich, increasing temperature glide.

\section{ACKNOWLEDGMENT}

The financial support for this experimentation by Government College of Engineering, Aurangabad (India) through TQIP Phase II is prominently respected

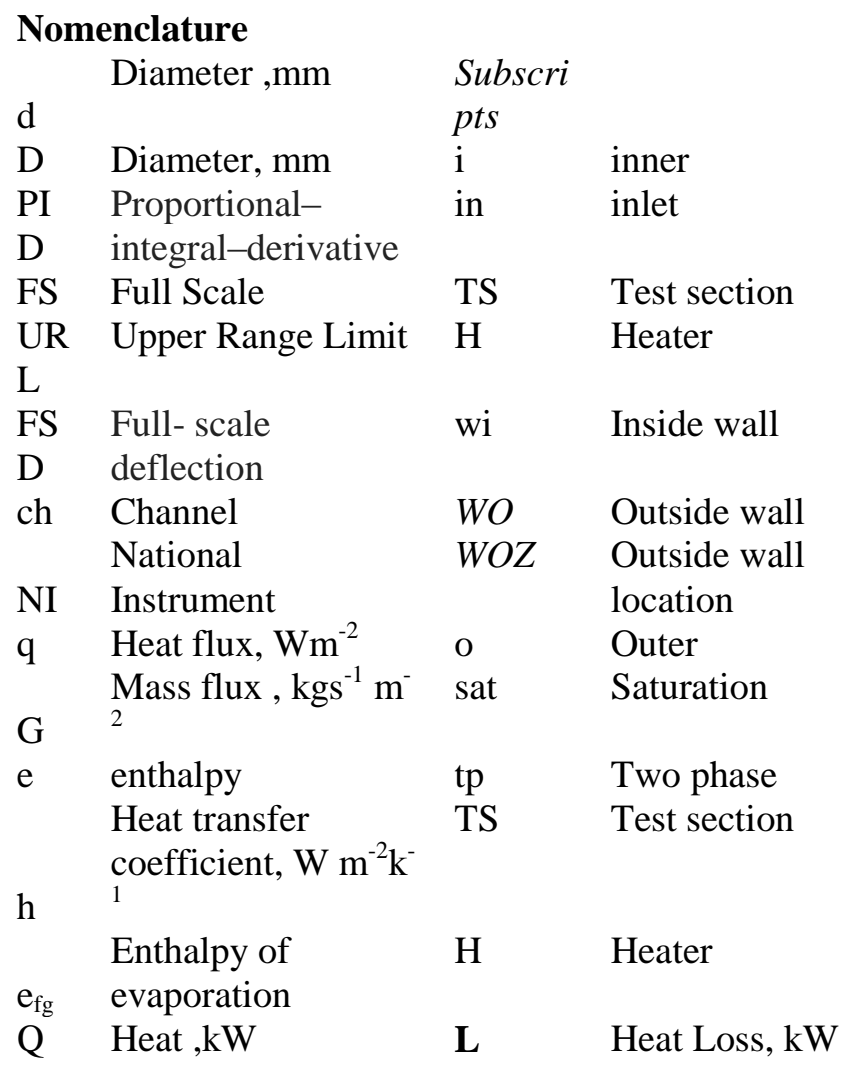




$\begin{array}{llll}\mathrm{T} & \text { Temperature } & \mathrm{S} & \text { Surface } \\ \mathrm{x} & \text { Vapor quality } & & \\ \mathrm{A} & {\text { Area, } \mathrm{m}^{2}} & & \end{array}$

\section{References}

[1] Arijit Kundu, Ravi Kumar, Akhilesh Gupta, 2014a.Comparative experimental study on flow boiling heat transfer characteristics of pure and mixed refrigerants. Int. J. Refrigeration 45,136-147.

[2] Arijit Kundu, Ravi Kumar, Akhilesh Gupta, 2014b.Flow boiling heat transfer characteristics of R407C inside a smooth tube with different tube inclinations. Int. J. Refrigeration 45, 1-12

[3] A.Kundu,R.Kumar,A.Gupta,2014.Performance comparison of zeotropic and azeotropic refrigerants in evaporation through inclined tubes.10th International Conference on Mechanical Engineering, ICME 2013,Science Direct, Procedia Engineering 90(2014) 452-458.

[4] A. Greco, 2008.Convective boiling of pure and mixed refrigerants: An experimental study of the major parameters affecting heat transfer. Int. J. Heat and Mass Transfer 51, 896-909.

[5] C.Aprea, A.Greco, A.Rosato, 2008. Comparison of R407C and R417A heat transfer coefficients and pressure drops during flow boiling in a horizontal smooth tube. Energy Conversion and Management 49, 1629-1636.

[6] C. Aprea, F. de Rossi, A. Greco, 2000.Experimental evaluation of R22 and R407C evaporative heat transfer coefficients in a vapor compression plant. Int. J. Refrigeration 23, 366- 377.

[7] C.A. Chen, W.R. Chang, K.W. Li, Y.M. Lie, T.F. Lin, 2009.Subcooled flow boiling heat transfer of $\mathrm{R}-407 \mathrm{C}$ and associated bubble characteristics in a narrow annular duct. Int. J. Heat and Mass Transfer $52,3147-3158$.

[8] Chi-chuan Wang, Ching-shan Chiang, 1997.Two phase heat transfer characteristics for R-22/R-407C in a 6.5-mm smooth tube. Int. J. Heat and Fluid Flow 18,550-558.

[9] Chen J.C, 1966. A correlation for boiling heat transfer to saturated fluids in convective flow. Industrial and Engineering Chemistry, Process Design and Development 5(3), 322-329.

[10] Enrique Torrela, Joaquin Navarro-Esbri, Ramon Cabello,2006.Boiling heat-transfer coefficient variation for R407C inside horizontal tubes of a refrigerating vapour-compression plant's shell-andtube evaporator. Applied Energy 83,239-252.

[11] F.C. Hsieh, K.W. Li, Y.M. Lie, C.A. Chen, T.F. Lin, 2008.Saturated flow boiling heat transfer of R407C and associated bubble characteristics in a narrow annular duct. Int. J. Heat and Mass Transfer 51, 3763-3775.

[12] Julio Cesar Passos, Vinicius Fernando Kuser, Phillipe Haberschill, Monique Lallemand, 2003. Convective boiling of R-407C inside horizontal microfin and plain tubes. Experimental Thermal and Fluid Science 27, 705-713.

[13] J.R. Thome, R.A.W. Shock, 1984. Boiling of multicomponent liquid mixture. Advances in Heat Transfer 16, 59-156.

[14] K. Stephan, 1995. Two-phase heat exchange for new refrigerants and their mixtures. International Journal of Refrigeration 18 (3), 198-209.

[15] L.E. Scriven, 1959. On dynamics of phase growth, Chem. Eng. Sci. 10 (1/2) 1-13.

[16] M.A.Kedzierski, J.H.Kim, D.A.Diddion, 1992. Causes of the apparent heat transfer degradation for refrigerant mixtures. ASME HTD-Vol.197, Two-Phase Flow and Heat Transfer, 149-158.

[17] Mirza M.Shah, 1976. A new correlation for heat transfer during boiling flow through pipes. ASHRAE Tr.82 (2), 66-85.

[18] P.Rollmann, K.Spindler, H. Muller-Steinhagen, 2011.Heat transfer, pressure drop and flow patterns during flow boiling of R407C in a horizontal microfin tube. J. Heat Mass Transfer 47,951-961.

[19] S.Wellsandt, L.Vamling, 2005. EvaporationofR407C and R410A in a horizontal herringbone microfin tube: heat transfer and pressure drop. Int. J. Refrigeration 28, 901-911.

[20] S.G.Kandlikar, 1990.A general correlation for Saturated Two-Phase Flow Boiling Heat Transfer inside Horizontal and Vertical Tubes. ASME J. Heat Mass Transfer 112, 219-228. 
[21] T.Y. Choi, Y.J. Kim, M.S. Kim, S.T. Ro,2000.Evaporation heat transfer of R-32, R-134a, R32/134a, and R-32/125/134a inside a horizontal smooth tube. Int. J. Heat and Mass Transfer 43, 3651-3660.

[22] Waldemar Targanski, Janusz T. Cieslinski, 2007.Evaporation of R407C/oil mixtures inside corrugated and micro-fin tubes. Applied Thermal Engineering 27, 2226-2232. 